mercury is probably due to adsorption on to the glass walls and rubber stopper. ${ }^{2}$

Everyone is exposed to small amounts of environmental mercury through food, water, and air. The upper limit for the urine mercury concentration in "normal" people is generally accepted as below $20 \mu \mathrm{g} / 1,{ }^{4}$ although considerable geographical variation exists. Thus even when $30 \mu \mathrm{g} / \mathrm{l}$ was taken as the upper limit for urine mercury concentrations 19 of our 26 patients had raised values. No correlation was found, however, between the urine mercury concentration and the age of the patient, the IgG dose, or the duration of treatment.

Few data are available on the quantitative evaluation of long-term exposure to organic mercury compounds. In one case of acute organic mercury poisoning from thiomersal a calculated total mercury dose of $280 \mathrm{mg}(0.14 \mathrm{mg} / \mathrm{kg} /$ day $)$ was administered over three months as a plasma preservative to a 13-year-old boy with protein-losing enteropathy: the urine mercury concentration was $5.3 \mathrm{mg} / 1 .{ }^{5}$ In contrast, four other patients transfused with plasma containing $0.01 \%$ thiomersal as preservative were excreting 50-600 $\mu \mathrm{g}$ mercury daily after consequent mercury doses of 3-210 mg but developed no acute symptoms or signs. ${ }^{5}$ In experiments thiomersal was given intravenously to 21 patients in doses up to $250 \mathrm{mg}$ mercury and the subjects observed from one to 62 days after administration. ${ }^{\circ}$ "Nephritis" was reported in one case, and thrombophlebitis in another; no other symptoms were observed.

In our series the total estimated mercury dosage in patients with hypogammaglobulinaemia ranged from 4 to $734 \mathrm{mg}$ (mean $157 \mathrm{mg}$ ), whereas the intensity of exposure was low in view of the prolonged treatment periods, ranging from six months to 17 years (mean 6.5 years). None of our 26 patients had overt clinical evidence of mercury toxicity. ${ }^{7}$ Neurological or intestinal symptoms that were present in our patients usually predated treatment and were attributed to the well-recognised complications of antibody deficiency. Three other patients (not included here) had uneventful pregnancies and gave birth to healthy children while receiving regular replacement therapy.

The urine mercury concentration may be considered to be an unreliable index of individual exposure to mercury, especially to alkyl mercury compounds, but urinary concentrations are often used to control exposure and evaluate risks in exposed subjects. Hence most patients with hypogammaglobulinaemia are theoretically at risk from mercury exposure, and although no clinical evidence of toxicity is yet apparent, physicians responsible for such patients must be alert to the need for continued, long-term, detailed clinical examination to detect any subtle disturbances ${ }^{7}$ that may occur.

\section{References}

${ }^{1}$ Medical Research Council, Hypogammaglobulinaemia in the United Kingdom. London, HMSO, 1971.

2 Wiener, S, fournal of Pharmacy and Pharmacology, 1955, 7, 118.

${ }^{3}$ Lindstet, G, Analyst, 1970, 95, 264.

4 World Health Organisation, WHO Occupational Health, 1966, 66, 39.

5 Suzuki, T, fournal of the fapanese Medical Association, 1969, 61, 1051.

6 Powell, H M, and Jamieson, W A, American fournal of Hygiene, 1931, 13, 269.

${ }^{7}$ Skerfving, S, and Vostal, J, in Mercury in the Environment: An Epidemiological and Toxicological Appraisal, ed L Friberg and J Vostal, p 93. Cleveland, C R C Press Inc, 1972.

(Accepted 21 May 1979)

\title{
Relation between medicines sweetened with sucrose and dental disease
}

\author{
I F ROBERTS, G J ROBERTS
}

British Medical fournal, 1979, 2, 14-16

\section{Summary and conclusions}

The teeth of 44 children aged under 6 years who had been taking syrup medicines regularly for at least six months were compared with those of a control group of 47 children of similar ages. Dental disease was assessed by measuring dental caries, dental plaque, and gingivitis. The children who were receiving sucrose-based medicines had significantly more carious teeth and gingivitis.

It is concluded that sucrose-based medicines continuously administered to children cause dental caries and gingivitis. Liquid medicines for children should be either unsweetened or sweetened with non-cariogenic substances.

Department of Child Health, St George's Hospital, London SW17 0QT I F ROBERTS, MB, MRCP, senior registrar

Department of Children's Dentistry and Orthodontics, Royal Dental Hospital, London WC2H 7LJ

G J ROBERTS, BDS, PHD, senior lecturer in children's dentistry

\section{Introduction}

Children with chronic diseases often require long-term medication. To improve palatability and perhaps patient compliance pharmaceutical companies supply many liquid medicines sweetened with sucrose. Sufficient evidence has now accrued from dental studies to support the relation between bacterial dental plaque, sucrose (or other fermentable carbohydrate), and the principal oral diseases of dental caries, ${ }^{1}$ gingivitis, and periodontal disease. ${ }^{2}$ We designed the present study to test the hypothesis, formulated from clinical impressions, that children taking liquid medicine containing sucrose on a long-term basis suffer more dental caries, plaque accumulation, and gingivitis than others.

\section{Patients and methods}

A paediatrician (IR) selected children for the investigation from hospital outpatients. They were aged between 9 months and 6 years, had chronic medical disorders, and had been attending hospital outpatient clinics regularly for at least six months. The study group comprised 44 children who had been prescribed liquid medicines on a daily basis throughout the preceding six months or longer. In all cases the nature of the drug and the frequency of prescription were verified by examining the hospital records. The sweetening agent was confirmed to be sucrose. A control group was formed of 47 children of similar ages who either received no medication or took medication in tablet form. 
Children who had taken liquid medicine on average more than one day in 10 were excluded from the control group, and those with medical disorders requiring major modifications to the carbohydrate content of their diet, such as diabetes mellitus and obesity, were excluded from both groups. The study group comprised 12 children aged 9 months to 3 years and 32 aged 3-6 years (mean age 46.7 months), while the control group comprised 18 children aged 9 months to 3 years and 29 aged 3-6 years (mean age 41.3 months; not significantly different). Table I shows further details of the children in the two groups. The investigation was approved by the hospital and medical school ethical committee, and all except one of the parents who were approached agreed to allow their child to be included in the study.

TABLE I-Numbers of patients with various diseases and mean total caries scores in study and control groups

\begin{tabular}{|c|c|c|c|c|c|}
\hline & $\begin{array}{l}\text { Nervous } \\
\text { system } \\
\text { (mostly } \\
\text { with fits) }\end{array}$ & $\begin{array}{l}\text { Respiratory } \\
\text { system } \\
\text { (mostly } \\
\text { asthma) }\end{array}$ & $\begin{array}{l}\text { Urinary } \\
\text { tract } \\
\text { infection }\end{array}$ & Others & Total \\
\hline & \multicolumn{5}{|c|}{ No of patients in group } \\
\hline \multirow[t]{2}{*}{$\begin{array}{l}\text { Study group } \\
\text { Control group }\end{array}$} & $\begin{array}{l}22 \\
31\end{array}$ & $\begin{array}{l}9 \\
6\end{array}$ & $\begin{array}{r}11 \\
1\end{array}$ & $\begin{array}{l}2 \\
9\end{array}$ & $\begin{array}{l}44 \\
47\end{array}$ \\
\hline & \multicolumn{5}{|c|}{ Mean total carious score $(D E F(S))$} \\
\hline $\begin{array}{l}\text { Study group } \\
\text { Control group }\end{array}$ & $\begin{array}{l}5.22 \\
1.67\end{array}$ & $\begin{array}{l}0.45 \\
2 \cdot 33\end{array}$ & $\begin{array}{l}7.63 \\
0.00\end{array}$ & $\begin{array}{l}17 \cdot 5 \\
0.11\end{array}$ & $\begin{array}{l}5.55 \\
1.26\end{array}$ \\
\hline
\end{tabular}

$\operatorname{DEF}(\mathbf{S})=$ Decayed, extracted, and filled surfaces.

It was virtually impossible to arrange the dental examinations for the same occasion as the child's routine visit to the medical outpatient clinic. As most parents were unwilling to bring their children to hospital on a separate occasion for dental examination only, most of the children were seen in their own homes. The examinations were all made by one dental surgeon (GR), who was unaware of each patient's drug or medical history until after the examination had been completed. The examination was carried out using a dental mirror and a pen torch. When the first permanent molars were present the fissures were gently explored with a sharp dental probe. The criteria used for dental caries, plaque, and gingivitis were based on those accepted for dental epidemiological studies. ${ }^{34}$ For dental caries each tooth surface in the mouth was recorded as sound, carious, filled, exfoliated, or extracted. A filled surface with recurrent caries was classified as carious. From these data the indices for carious (decayed (D)), extracted (E), and filled (F) surfaces (S) were derived. These indices were added together and expressed as $\operatorname{DEF}(\mathrm{S})$ for decayed, extracted, and filled surfaces, $\mathrm{DF}(\mathrm{S})$ for decayed and filled surfaces, and $E(T)$ for extracted teeth.

Bacterial dental plaque was assessed by inspecting the distal, buccal, mesial, and lingual or palatal surfaces of the lower left second deciduous molar, the lower left deciduous central incisor, the lower right deciduous first molar, the upper left deciduous first molar, the upper right deciduous central incisor, and the upper right deciduous second molar. Plaque was scored 0 if absent, 1 if covering less than the gingival third, and 2 if covering more than the gingival third of the tooth surface. The total plaque score was divided by the number of teeth used to give a plaque index for each patient. If one or more of the teeth designated was absent the plaque score was derived from the reduced number of teeth present.

Gingivitis was scored 0 if absent, 1 if slight, and 2 if gross. The same teeth were used as for the plaque assessment, and a gingival index for each patient was derived in the same way.

Repeatability - In order to validate the repeatability of the dental assessment one in seven of the patients was re-examined on the same day. Repeatability studies were also performed on two separate groups of nursery schoolchildren aged 3-5 years. One group was seen before and one after the main study. The interval between their individual examinations was one week. Table II gives the Spearman rank correlation coefficient for the repeatability tests on the various indices, which confirmed that the dental surgeon was sufficiently consistent in his assessments for the purposes of the study.

Recording of data and questionnaire-During the dental examination the observations were recorded by the paediatrician on specially prepared data sheets using code numbers. Immediately after the examination the paediatrician completed a questionnaire for each patient (see appendix), the questions being answered by one or both parents. When appropriate, details were checked by comparing them with the hospital case records. The questionnaire was designed to
TABLE II-Results of studies carried out on two groups of nursery schoolchildren and some children in main study to test repeatability of observations made in main study

\begin{tabular}{|c|c|c|c|c|c|c|}
\hline \multirow{3}{*}{ Indices of dental disease } & \multicolumn{4}{|c|}{ Nursery schoolchildren } & \multirow{2}{*}{\multicolumn{2}{|c|}{$\begin{array}{l}\text { Children in } \\
\text { main study } \\
(n=12)\end{array}$}} \\
\hline & \multicolumn{2}{|c|}{$\begin{array}{l}\text { Before main study } \\
(\mathrm{n}=22)\end{array}$} & \multicolumn{2}{|c|}{$\begin{array}{l}\text { After main study } \\
\quad(n=21)\end{array}$} & & \\
\hline & Rs & $\mathbf{P}$ & Rs & $\mathbf{P}$ & $\mathbf{R s}_{\mathrm{s}}$ & $\mathbf{P}$ \\
\hline $\begin{array}{l}\text { Carious index } \mathrm{DEF}(\mathrm{S}) \\
\text { Carious index DF(S) } \\
\text { Plaque index } \\
\text { Gingival index }\end{array}$ & $\begin{array}{l}0.78 \\
0.78 \\
0.58 \\
0.62\end{array}$ & $\begin{array}{l}0 \cdot 001 \\
0.001 \\
0 \cdot 01 \\
0.005\end{array}$ & $\begin{array}{l}0 \cdot 75 \\
0 \cdot 75 \\
0 \cdot 40 \\
0 \cdot 20\end{array}$ & $\begin{array}{l}0 \cdot 001 \\
0 \cdot 001 \\
0 \cdot 04(\mathrm{NS}) \\
0 \cdot 15(\mathrm{NS})\end{array}$ & $\begin{array}{l}1.00 \\
1.00 \\
0.96 \\
0.95\end{array}$ & $\begin{array}{l}0.001 \\
0.001 \\
0.001 \\
0.001\end{array}$ \\
\hline
\end{tabular}

$R_{S}=$ Spearman rank correlation coefficient.

DEF(S) = Decayed, extracted, and filled surfaces.

NS $=$ Not significant.

provide details of medication and other factors related to dental health and disease in childhood.

Statistical analysis-Differences in the ages and dental indices between the study and control groups were analysed using the MannWhitney $U$ test. Differences between the groups in data derived from the questionnaire were analysed by means of the $\chi^{2}$ test for independent samples.

\section{Results}

The 44 children in the study group had a total of 244 carious tooth surfaces and 15 teeth extracted; the 47 children in the control group had 65 carious surfaces and no extracted teeth. Table III gives the mean scores for the various dental indices and shows that a significant difference in the scores for dental caries and gingivitis was apparent between the two groups. There was no significant difference in the amount of plaque between the two groups. Analysis of the information obtained from the questionnaire showed that there was no significant difference between the two groups in the following factors, which might be related to dental decay: previous dental treatment, type of milk feeding, additions to cows' milk formulae, use of a dummy with or without reservoir, between-meal snacks, bedtime drinks, vitamin supplements, sweets and soft drinks and frequency of consuming these, administration of fluoride tablets, age of onset and frequency of tooth brushing, and type of toothpaste.

TABLE III-Comparative scores of indices of dental disease in study and control groups

\begin{tabular}{lccc}
\hline \multirow{2}{*}{ Indices of dental disease } & \multicolumn{2}{c}{ Mean score } & \multirow{2}{*}{$\begin{array}{c}\text { Significance } \\
\end{array}$} \\
\cline { 2 - 3 } & $\begin{array}{c}\text { Study group } \\
(\mathbf{n}=\mathbf{4 4})\end{array}$ & $\begin{array}{c}\text { Control group } \\
(\mathrm{n}=\mathbf{4 7})\end{array}$ & \\
\hline Total carious score (DEF(S)) & 5.55 & 1.26 & 0.02 \\
Carious score for carious and & 3.82 & 1.26 & 0.03 \\
filled surfaces (DF(S)) & 0.34 & 0.00 & $0.29(\mathrm{NS})$ \\
Extracted teeth (E(T)) & 0.87 & 0.55 & $0.06(\mathrm{NS})$ \\
Plaque index & 0.91 & 0.51 & 0.03 \\
Gingival index & & & \\
\hline
\end{tabular}

$\mathrm{DEF}(\mathrm{S})=$ Decayed, extracted, and filled surfaces.

$\mathrm{DF}(\mathrm{S})=$ Decayed and filled surfaces.

$\mathrm{E}(\mathrm{T})=$ Extracted teeth.
NS $=$ Not significant.

\section{Discussion}

We did not intend in this study primarily to relate dental disease to underlying medical disorder or type of drug prescribed. The caries scores in table I imply an increased prevalence of caries in children most likely to be receiving anticonvulsants and antibiotics, and less caries in children receiving bronchodilators, but the numbers in each diagnostic subgroup were small and no firm statistical conclusions may be drawn from them. Children receiving long-term antibiotics develop appreciably less caries than others, ${ }^{5}$ but this effect has not been shown in children taking sulphadiazine. ${ }^{\circ}$ In our study any 
tendency for antibiotics to reduce dental caries would have narrowed the difference in the amount of caries between the study and control groups. No drugs prescribed to patients in this study affect the flow or composition of saliva, and during the clinical examinations no patients were found to have dry mouths. The study and control groups were matched closely. Apart from the sucrose-based medicines taken by the study group no difference was found between the groups for all the other factors known to influence the prevalence of caries analysed from the questionnaire.

Our results show that chronic administration of liquid medicines sweetened with sucrose increases the incidence of dental caries and gingivitis in children. Thus children with chronic disorders requiring long-term medication may be contracting dental disease as a side effect of the treatment for their principle illness. This increase in dental disease, particularly dental caries, may result in an increased number of dental extractions. A general anaesthetic is usually necessary for such extractions in young children. This adds to the morbidity of children who are already suffering from chronic diseases.

The difference in the amount of plaque between the study and control groups was just outside levels usually accepted as significant $(P=0.06)$. This was surprising, as plaque is the principle aetiological factor in both caries and gingivitis, which were significantly more common in children taking liquid medicine. The explanation is probably that during the investigation some children's teeth were given a special clean "as the dentist was coming to inspect them." This information was often given with the initial greeting when we visited each home. In many children plaque had been removed by cleaning within the one or two hours preceding the inspection. These children would have been given a low plaque score, but their caries and gingival scores would have remained unchanged as gingival inflammation takes several days to resolve once plaque has been removed.

We compared only the dental condition of patients with chronic medical disorders receiving liquid medicines containing sucrose with that of patients not receiving such medicines, and did not attempt to make a comparison between the incidence of dental disease in chronically sick children and the general population. The children in the study were much younger than those in most population study reports, and the indices used in the present study were not identical with those used by other investigators, although they were similar. The poor dental state of the children in the present investigation highlights the absence of regular dental care for such children. Preoccupation with the principle medical problem often results in neglect of other, perhaps less obvious, facets of the child's total health. Neglect of oral health has unpleasant consequences, and the child with severe toothache or a dental abscess may have to undergo the distressing experience of an extraction.

The need to use sucrose as a sweetening agent in liquid medicines, particularly in paediatric medical practice, should be seriously questioned. Other non-fermentable sweetening agents such as sorbitol or xylitol may be used instead. We suggest that pharmaceutical manufacturers should be encouraged to produce liquid medicines with alternative sweeteners. Indeed, the need to use sweeteners at all should be reassessed. The results of the present investigation indicate that much dental disease might be prevented by ensuring that all children with chronic ill health receive regular preventive and conservative dental care and that those requiring regular medication are not given liquid medicines in a sucrose base.

We wish to thank Professors J K Lloyd and W J B Houston for their advice; and Drs R J West, O G Brooke, R Wilson, and D Lawson and Professor O H Wolff for permission to study their patients.

\section{References}

1 Winter, G B, and Murray, J J, Dental Caries, Its Causes, Prevention and Control, ed F J Harty and D H Roberts. Bristol, John Wright and Sons, 1974.

2 Cohen, B, in The Essential Nature of Periodontal Disease, ed B Cohen and I Kramer. London, Heinemann, 1976.

${ }^{3}$ Davies, G N, Horowitz, H S, and Wada, W, Community Dentistry and Oral Epidemiology, 1973, 1, 68.

4 Loe, H, and Silness, J, Acta Odontologica Scandinavica, 1963, 21, 533.

${ }^{5}$ Handelman, S L, Mills, J R, and Hawes, R R, Fournal of Oral Therapeutic and Pharmacology, 1966, 2, 338.

${ }^{6}$ Fleming, W J, Sandham, H J, and Thompson, G W, Archives of Oral Biology, 1978, 23, 591.

(Accepted 23 May 1979)

\section{Appendix}

QUESTIONNAIRE FILLED IN FOR EACH CHILD

Name:

Examination No:

Code No

(1) Dental treatment:

(a) has child attended dentist?

(b) age commenced?

(c) fillings ?

(d) extractions ?

(2) Age at which deciduous incisors erupted

(3) Condition of teeth on eruption

(4) Dietary habits:
(a) breast feeding? (i) age discontinued
(b) bottle feeding ?
(i) age started
(ii) age discontinued
(iii) contents sweetened
(c) was a dummy used?
(i) without a reservoir
(ii) with a reservoir
(iii) contents sweetened
(d) between-meal snacks?

(e) bedtime drinks?

(f) vitamin $\mathrm{A}, \mathrm{D}$, and $\mathrm{C}$ supplements ?

$(g)$ fluoride tablets?

(i) age begun

(ii) age stopped

(h) sweets or soft drinks ?

(i) once per week

(ii) once per day

(iii) more than once per day

(5) Oral hygiene (toothbrushing):

(a) age started?

(b) frequency per day?

(c) fluoride toothpaste?

(6) Were there abnormalities of birth ?

If yes, specify:

(a) pregnancy

(b) labour and delivery

(c) infancy (less than one month)

(7) Medical problems:

(a) main conditions ?

(b) secondary conditions?

(c) hospitalisation?

(i) main condition, number or times

(ii) other reasons, number of times

(8) Current medication:

$\begin{array}{ll}\text { yes } & \text { no } \\ \text { y } & \text { mth } \\ \text { yes } & \text { no } \\ \text { yes } & \text { no } \\ \text { y } & \text { mth } \\ \text { normal } & \text { abnorm }\end{array}$

normal abnormal

yes no

y mth

yes no

y mth

yes no

yes no

yes no

yes no

yes no

yes no

yes no

yes no

y mth

y mth

yes no

yes no

yes no

y mth

yes no

(ii)

Drug dose $\mathrm{mg} \mathrm{ml}$ times/day duration syrup tablet

yes yes

(9) Socioeconomic state:

(i) occupation of father

(ii) occupation of mother

(iii) number of brothers and sisters

(10) Comments about brothers and sisters

(11) Name and address of GP

Hospital notes

Patient thought to be taking drugs

regularly 